\title{
FIRElinks. Fire in the Earth System: Science \& Society ${ }^{\dagger}$
}

\section{Artemi Cerdà}

Soil Erosion and Degradation Research Group, Department of Geography, Valencia University, Valencia, Blasco Ibáñez 28, 46010-Valencia, Spain; artemio.cerda@uv.es † Presented at TERRAenVISION 2019, Barcelona, 2-7 September 2019.

Published: 21 May 2020

\begin{abstract}
FIRElinks is a EU-spanning network of scientists and practitioners involved in forest fire research and land management with backgrounds such as fire dynamics, fire risk management, fire effects on vegetation, fauna, soil and water, and socio-economic, historical, geographical, political perception and land management approaches. FIRElinks connect communities from different scientific and geographic backgrounds, allowing the discussion of different experiences and the emergence of new approaches to fire research. The main aim of FIRElinks is to power synergistic collaborations between European research groups and stakeholders with the objective to synthesise the existing knowledge and expertise, and to define a concerted research agenda which promotes an integrated approach to create fire-resilient landscapes, taking into account biological, biochemical and-physical, but also socio-economic, historical, geographical, sociological, perception and policy constraints. This is an urgent societal need due to expected further intensification and geographical spreading of wildfire regimes under Global Change. FIRElinks is composed of 35 European countries national representants (plus 10 non-EU countries members) and currently is registered 260 participants. Although based in the collaboration of scientists of different backgrounds and regions, the main objective is to share with stakeholders from different origins the past, present and future management of fire in agriculture, forest, scrub and grass lands.
\end{abstract}

Keywords: fire; Europe; management; stakeholders; sustainability

Acknowledgments: This abstract was written as a result of the collaboration that was initiated due to the COST Action "Fire in the Earth System: Science \& Society" (FIRElinks) CA18135.

(C) 2020 by the authors. Licensee MDPI, Basel, Switzerland. This article is an open access article distributed under the terms and conditions of the Creative Commons Attribution (CC BY) license (http://creativecommons.org/licenses/by/4.0/). 